\title{
High reward from low-abundance methane molecules
}

Methane is ubiquitous on Earth and is produced and consumed through various processes, including biological reactions (such as methanogenesis and methane oxidation by microbes), the thermal breakdown of organic matter during burial, and abiotic production from, for example, $\mathrm{H}_{2}$ and $\mathrm{CO}_{2}$. These processes often interact and overlap, and it is crucial to understand how and when they do so in order to investigate methane dynamics in our warming planet. However, it is difficult to distinguish the various competing methane consumption and production reactions when they co-occur in the same environment, as traditional methane isotopic measurement techniques cannot distinguish between them confidently without additional information about the system. A new tool, the measurement of "clumped" isotopes of methane, now provides this capability.

Enabled by new instrumentation — such as high-resolution gas source isotope ratio mass spectrometers and TILDAS (Tunable Infrared Laser Direct Absorption Spectrometers) the technique characterizes the abundance of methane and its different isotopes, including the singly isotopically substituted $\left({ }^{13} \mathrm{CH}_{4}\right.$ and $\left.\mathrm{CH}_{3} \mathrm{D}\right)$ and the rare isotopes $\left({ }^{13} \mathrm{CH}_{3} \mathrm{D}\right.$ and $\left.{ }^{12} \mathrm{CH}_{2} \mathrm{D}_{2}\right)$. Given that different (bio)geochemical processes produce different isotopic ratios (for example, the combination of ${ }^{13} \mathrm{CH}_{3} \mathrm{D}$ and ${ }^{12} \mathrm{CH}_{2} \mathrm{D}_{2}$ molecules differs for microbial and abiotically produced methane), this measurement offers insight into how methane is cycled in situ. The clumped isotope technique has applications across different environments, such as hydrothermal

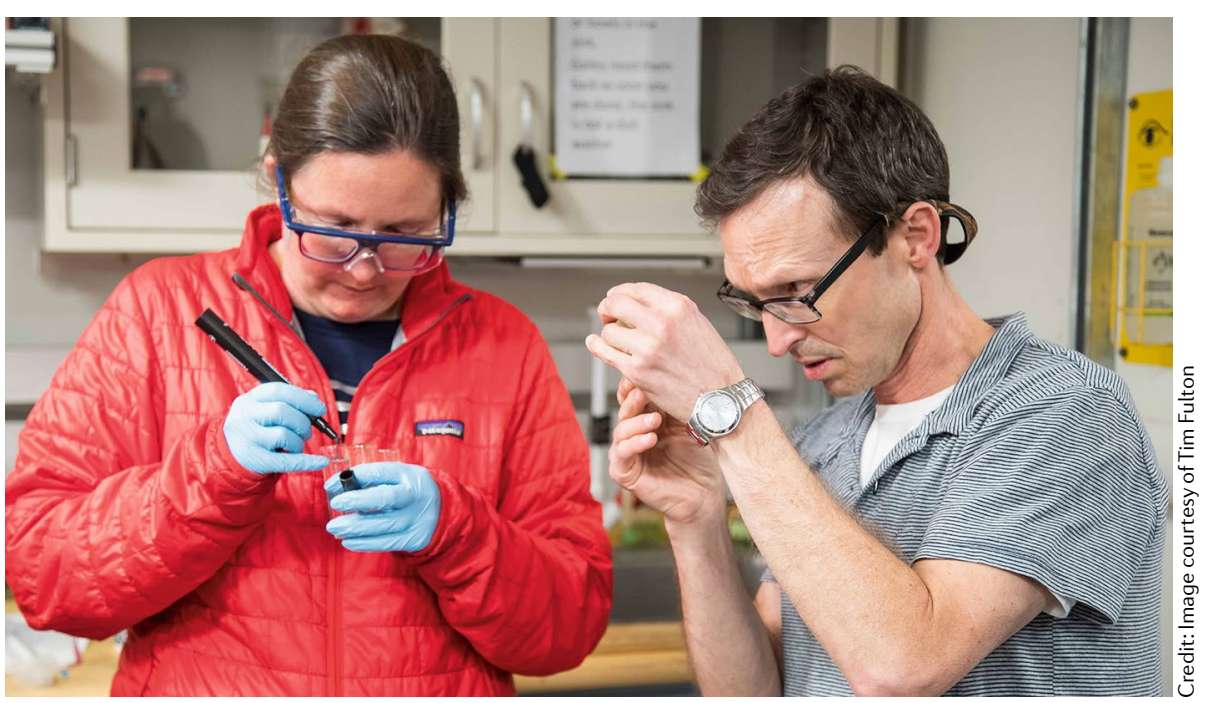

vents, serpentinizing systems, or deeply buried, organic-poor marine sediment.

Although measuring clumped methane isotopes to characterize methane biogeochemistry is a relatively young technique, it has already been broadly applied. In North American continental sedimentary basins, for example, the technique has been used to reveal contrasting chemical processes between Silurian-age strata (where methane was mainly produced through thermal action and microbial methanogenesis) and Devonian-age strata (where microbial methanogenesis and methane oxidation dominated). Furthermore, when combined with microbiological studies and the measurement of other geochemical parameters, carbon cycling in hydrocarbonbearing hydrothermal sediments can be studied in unprecedented detail, as done on the 2019 International Ocean Discovery Program Expedition to the Guaymas Basin (Gulf of California). Clumped methane isotopes also stand poised to reveal more about methane throughout the solar system, such as on Titan, which has a methane-based weather system, and Mars, where gasps of tiny amounts of methane have been observed. However, those applications are far off, so for now clumped isotopes of methane can offer new insights into systems a little closer to home.

Jeanine L. Ash

Department of Earth, Environmental and Planetary Sciences, Rice University, Houston, TX, USA. e-mail:jeanine.ash@rice.edu The author declares no competing interests. 